\title{
An Extremely Rare Case Report of Foramen Magnum Dermoid Cyst Presenting as an Acute Progressive Neurologic Deficit
}

\author{
Ahmad Rezaee Azandaryani1, Mehrdad Taghipour ${ }^{2 *}$, Leili Ebrahimi Farsangi ${ }^{3}$ \\ ${ }^{1}$ Radiology Department, Hamadan University of Medical Sciences, Besat Hospital, Hamadan, Iran \\ ${ }^{2}$ General Surgery Department, Hamadan University of Medical Sciences, Besat Hospital, Hamadan, Iran \\ ${ }^{3}$ Alborz University of Medical Sciences, Shahid Rajaee Hospital, Karaj, Iran \\ Email: *mehrdadtaghipour@gmail.com
}

How to cite this paper: Azandaryani, A.R. Taghipour, M. and Farsangi, L.E. (2020) An Extremely Rare Case Report of Foramen Magnum Dermoid Cyst Presenting as an Acute Progressive Neurologic Deficit. Case Reports in Clinical Medicine, 9, 74-80. https://doi.org/10.4236/crcm.2020.93012

Received: February 16, 2020

Accepted: March 23, 2020

Published: March 26, 2020

Copyright $\odot 2020$ by author(s) and Scientific Research Publishing Inc. This work is licensed under the Creative Commons Attribution International License (CC BY 4.0).

http://creativecommons.org/licenses/by/4.0/

\begin{abstract}
Intracranial dermoid cysts are nonneoplastic lesions that present a rare clinical entity. They account for $0.04 \%$ to $0.6 \%$ of all intracranial tumors. Such cystic lesions usually contain different ectodermal derivatives including hairs, sebaceous glands, apocrine gland and teeth. Dermoid cysts of foramen magnum occur very rarely, with few cases reported in the literature. Computed tomography (CT) and magnetic resonance imaging (MRI) are two main diagnostic tools. Here in this paper, we described a case of intracranial (foramen magnum) dermoid cyst presented with neurologic deficits that completely removed surgically.
\end{abstract}

\section{Keywords}

Cyst, Dermoid, Foramen Magnum, Radiology

\section{Introduction}

Dermoid cysts are congenital ectodermal inclusion cysts that contain varying amounts of ectoderm derivatives. Epidermoid cyst generated from squamous epithelial cells and doesn't show dermal derivatives such as hair follicles. Teratomas consist of ectodermal, mesodermal and endodermal tissue [1] [2].

Clinical presentation of patients with brain dermoid lesions is variable. They may be incidentally detected on brain computed tomography (CT) or magnetic resonance imaging (MRI) for complaints such as head trauma or headaches. They may cause a large mass effect and resulted in signs and symptoms related to compression of adjacent brain tissue structures [3] [4]. 
There are several cases of spontaneous rupture of dermoid cyst or rupture after head trauma [5] [6] [7] [8]. Rupture of dermoid lesions resulted in dissemination of dermoid cyst contents in to ventricles, subarachnoid or subdural spaces causing headache and seizures due to chemical meningitis or hydrocephalous [8] [9]. Intracranial dermoid lesions are usually located in midline such as suprasellar region. They may also occur in parasellar region or posterior fossa and cerebellar vermis [10]. Here in this case report study we presented a middle-aged woman with neurologic deficits related to dermoid cyst in foramen magnum that was confirmed by MRI and also pathologic evaluations.

\section{Case Presentation}

The reported case is a 45-year-old woman presented with progressive gate problems and upper limb pain, paresthesia and weakness to the neurology clinic of Sina Hospital, Hamadan-Iran in May 2019. She also complained of difficulty in swallowing and frequency at urination. In neurologic exam, there was no obvious cranial nerve dysfunction. Upper limb partial weakness was confirmed. Hoffmann's reflex was positive and deep tendon reflex at lower limbs was exaggerated. Gate was a normal limit.

At MRI exam heterogenous cystic structure measuring $40 * 25 * 15 \mathrm{~mm}$ at inferior portion of brain posterior fossa extending to upper cervical canal at $\mathrm{C} 1$ and C2 level was detected which resulted in compression on medulla and upper cervical cord. The lesion contains a high signal focus in T1 and T2 sequence. High intensity in $\mathrm{T} 1$ sequence could be suggestive of presence of fat in lesion or hemorrhage (Figures 1-4).

According to clinical evaluations and imaging findings, the patient was candidate for surgery and operated at concord position by posterior midline suboccipital

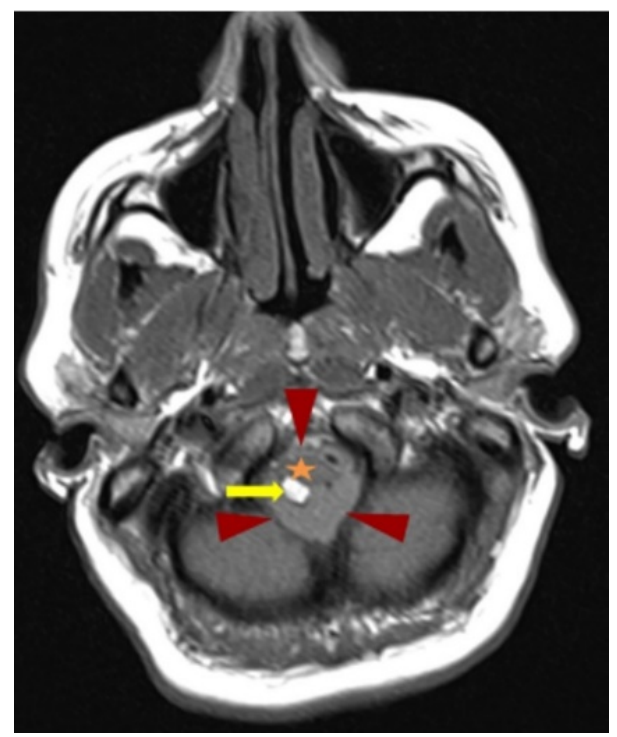

Figure 1. Axial T1 MRI at the level of foramen magnum shows intermediate signal intensity mass lesion encompasses medulla oblongata (asterisk) and caused mass effect (arrowheads) note high signal nodule in lesion due to fat component (yellow arrow). 


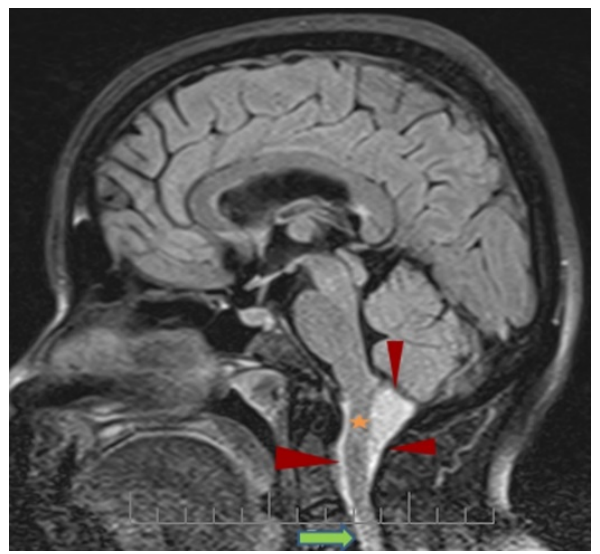

Figure 2. FLAIR image shows elegantly high signal intensity cystic mass lesion (red arrowheads) encompasses medulla oblongata (asterisk) and extended downward into spinal canal at the level of C3 vertebrae body (green arrow).

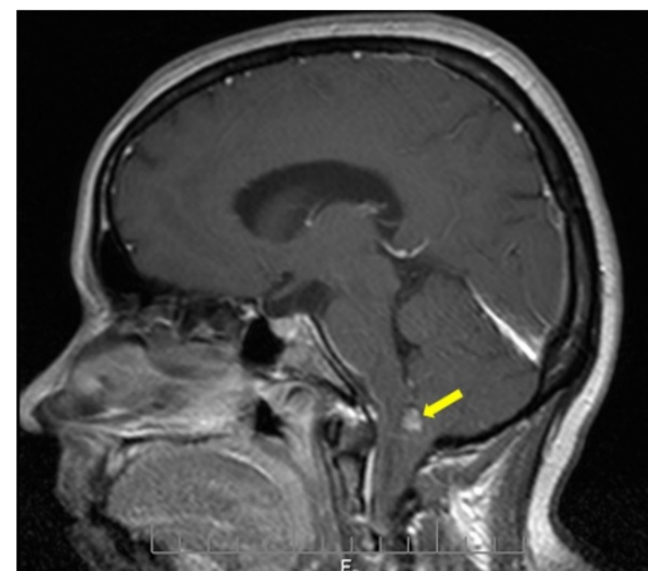

Figure 3. Sagittal T1 weighted images with gadolinium shows no enhancement of lesion, note high signal intensity nodule due to fat component (yellow arrow).

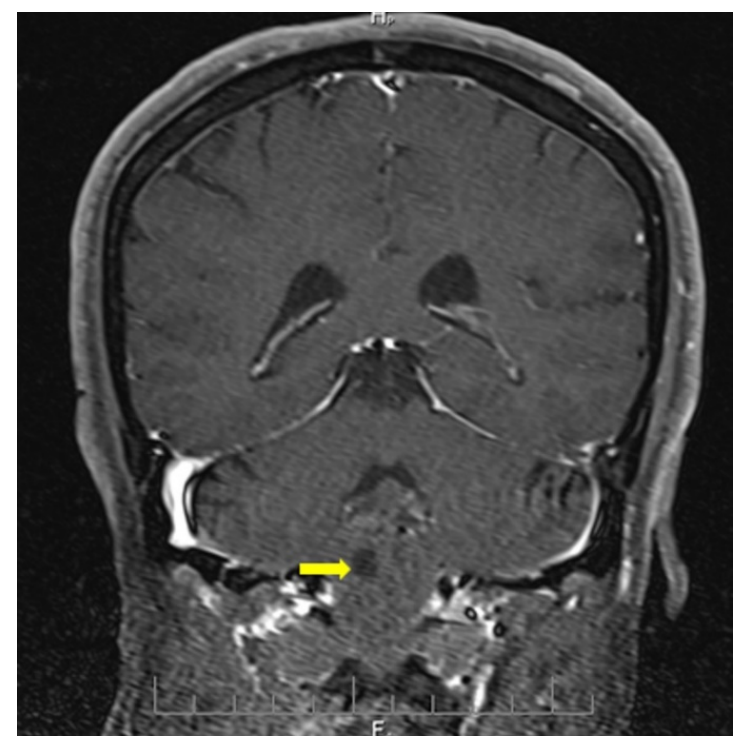

Figure 4. Coronal T1W contrast enhanced fat suppressed image shows no enhancement of lesion, note signal loss of fat component (yellow arrow). 
approach. The lesion has a distinct thin capsule which after opening liquid content with yellow color, fat like particle and a considerable amount of hair exited (Figure 5).

Ten days after surgery patient was discharged and showed gradual alleviation in signs and symptoms in follow up. Now the patient is 10 months out from surgery without recurrent or residual tumor.

\section{Discussion}

Intracranial dermoid cysts are benign congenital dysembryogenic lesion that are usually located midline. They are caused by embryological malformation during the development of the neural tube between the 3rd and 5th weeks [11]. This squamous epithelium lined cysts contain skin appendages such as nails, hair follicles, teeth and sebaceous glands [12]. About seven percent of dermoid affect the head and neck. They are frequently presented at the orbit, nose or in the lateral eyebrow. The age of occurrence in woman is between 20 and 36 years of age [13]. Our case was 45 years old. Dermoid cysts can be seen in associated with Goldenhar (oculoauriculo-vertebral dysplasia) and Klippel-Feil syndromes, sporadically.

Cranial dermoid cysts comprise $0.04 \%$ to $0.7 \%$ of intracranial tumors and are four to nine times less common than epidermoid cysts. Most symptoms happen due to their mass effect on neural structures. The clinical presentations are depending on the location of intracranial lesions [14]. Most of such cases are frequently localized on the midline portion of the brain interesting sellar, suprasellar and frontonasal regions. Posterior cranial fossa is a less common localization. Our patient had a distinct mass in the foramen magnum.

The most prevalent symptoms include focal headache (32\%), neurologic deficit, or meningitis. Less common presentations include visual field defects, seizures, exophthalmos, hydrocephalus, and oculomotor palsy [15]. Some cases of sudden death have also been reported followed by spontaneous rupture of dermoid

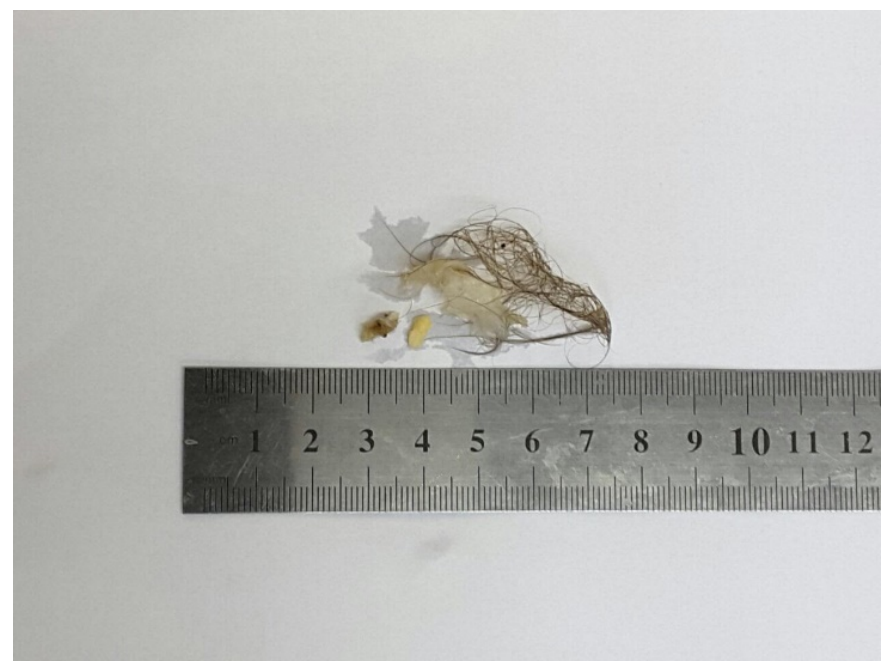

Figure 5. Removed dermoid cyst containing the hair, fatty tissue and keratinized tissue. 
cyst. In the present report, the patient was presented with progressive gate problems and upper limb pain, paresthesia and weakness.

An essential step in diagnosing these lesions is imaging studies. The differential diagnosis which is proposed based on the imaging findings includes epidermoid cysts, arachnoid cysts, cystic gliomas, lipomas, teratomas, and craniopharyngiomas [16].

On CT images, dermoid cysts appear as a uniloculated, well-delineated cystic mass with hypodensity from moderate to significant and some are present capsular calcification. MRI features include hyperintense signal on SE T1 sequences and heterogeneous hypo-hyperintense signal on FSE T2 [17].

Rupturing of dermoid cysts typically is seen as high-signal fat droplets within the subarachnoid spaces and intraventricular fat/CSF levels. In our case, the patient had no symptoms and signs of meningitis or hydrocephalus.

Surgical resection remains the treatment modality of choice. Tumors in foramen magnum can pose challenges for neurosurgeons [18]. By improving microsurgical techniques, the total resection is preferable. It is believed to reduce both postoperative chemical meningitis and tumor recurrence risk. Often the prognosis of patients with intracranial dermoid cysts who undergo surgery is favorable.

\section{Conclusion}

The presented case is such a rare radiologic finding that was successfully removed via surgery and precisely confirmed pathologically. We suggest that all clinicians especially radiologists, neurosurgeons and neurologists consider and keep dermoid tumor in their minds as the differential diagnosis of cystic lesions in foramen magnum. The preferred surgical planning can be guided by exact preoperative imaging.

\section{Acknowledgements}

Authors would like to thank Dr. Mahdi Arjipour for his valuable and constructive suggestions during the study procedures. His willingness to give his time so generously has been very much appreciated.

\section{Consent for Publication}

Written informed consent was obtained from the patient to participate in the treatment and publication.

\section{Conflicts of Interest}

The authors declare no conflicts of interest regarding the publication of this paper.

\section{References}

[1] Smirniotopoulos, J.G. and Chiechi, M.V. (1995) Teratomas, Dermoids, and Epidermoids 
of the Head and Neck. Radiographics, 15, 1437-1455. https://doi.org/10.1148/radiographics.15.6.8577967

[2] Osborn, A.G. and Preece, M.T. (2006) Intracranial Cysts: Radiologic-Pathologic Correlation and Imaging Approach. Radiology, 239, 650-664.

https://doi.org/10.1148/radiol.2393050823

[3] Venkatesh, S.K., Phadke, R.V., Trivedi, P. and Bannerji, D. (2002) Asymptomatic Spontaneous Rupture of Suprasellar Dermoid Cyst: A Case Report. Neurology India, 50, 480-483.

[4] Berhouma, M. (2010) Oiled Brain and Status Epilepticus: Intraventricular and Subarachnoid Rupture of a Temporal Dermoid Cyst. Journal of Medical Cases, 1, 94-97. https://doi.org/10.4021/jmc72w

[5] Asil, K., Gunduz, Y., Ayhan, L.T., Aksoy, Y.E. and Yildiz, C. (2013) Spontaneous Rupture of Intracranial Dermoid Tumor in a Patient with Vertigo. Computed Tomography and Magnetic Resonance Imaging Findings. Polish Journal of Radiology, 78, 79. https://doi.org/10.12659/PJR.889172

[6] Wang, Y.M., Chang, T.P., Lo, C.P. and Tu, M.C. (2013) Spontaneous Rupture of Intracranial Dermoid Cyst with Chemical Meningitis. Journal of Emergency Medicine, 44, e275-e276. https://doi.org/10.1016/j.jemermed.2012.06.023

[7] Luan, Y., Wang, H., Zhong, Y., Bian, X., Luo, Y. and Ge, P. (2012) Traumatic Hemorrhage within a Cerebellar Dermoid Cyst. International Journal of Medical Sciences, 9, 11. https://doi.org/10.7150/ijms.9.11

[8] Kim, I.Y., Jung, S., Jung, T.Y., Kang, S.S. and Kim, T.S. (2008) Traumatic Rupture of an Intracranial Dermoid Cyst. Journal of Clinical Neuroscience, 15, 469-471.

https://doi.org/10.1016/j.jocn.2006.10.028

[9] Esquenazi, Y., Kerr, K., Bhattacharjee, M.B. and Tandon, N. (2013) Traumatic Rupture of an Intracranial Dermoid Cyst: Case Report and Literature Review. Surgical Neurology International, 4, 80. https://doi.org/10.4103/2152-7806.113357

[10] Wani, A.A., Raswan, U.S., Malik, N.K. and Ramzan, A.U. (2016) Posterior Fossa Ruptured Dermoid Cyst Presenting with Hydrocephalus. Neurosciences, 21, 358. https://doi.org/10.17712/nsj.2016.4.20160280

[11] Lekgwara, P., Kelly, A., Neurosurgery, F.C. and Younus, A. (2019) A Challenging Case of an Intramedullary Dermoid Cyst of the Cervical Spine-A Literature Review. Interdisciplinary Neurosurgery, 18, Article ID: 100479. https://doi.org/10.1016/j.inat.2019.100479

[12] Triplett, T.M., Griffith, A., Hatanpaa, K.J. and Barnett, S.L. (2014) Dermoid Cyst of the Infratemporal Fossa: Case Report and Review of the Literature. Journal of Neurological Surgery Reports, 75, e33-e37. https://doi.org/10.1055/s-0033-1358795

[13] Choi, J.S., Bae, Y.C., Lee, J.W. and Kang, G.B. (2018) Dermoid Cysts: Epidemiology and Diagnostic Approach Based on Clinical Experiences. Archives of Plastic Surgery, 45, 512-516. https://doi.org/10.5999/aps.2018.00017

[14] Kumaran, S.P., Srinivasa, R. and Ghosal, N. (2019) Unusual Radiological Presentation of Intracranial Dermoid Cyst: A Case Series. Asian Journal of Neurosurgery, 14, 269-271. https://doi.org/10.4103/ajns.AJNS_304_17

[15] Moridi, A., Arab, M., Fazli, G. and Khayamzadeh, M. (2016) Clinical Points in Dermoid Cyst Management: A Review Article. Journal of Obstetrics Gynecology and Cancer Research, 1, e10034. https://doi.org/10.17795/ogcr-10034

[16] Shetty, S.R., Panigrahi, M. and Rao, S. (2013) Neurenteric Cyst at the Craniovertebral Junction: A Report of Two Cases. Asian Journal of Neurosurgery, 8, 188-191. https://doi.org/10.4103/1793-5482.125667 
[17] Patil, A., Kulkarni, V., Singh, G. and Sehrawat, P. (2016) Fourth Ventricle Epidermoid Tumor: Radiologic Findings. Medical Journal of Dr. D. Y. Patil Vidyapeeth, 9, 136-139. https://doi.org/10.4103/0975-2870.168001

[18] Survashe, P.T., Guthe, S.P., Velho, V. and Bhide, A. (2017) Ruptured Intracranial Dermoid: Case Report and Literature Review. Medical Journal of Dr. D. Y. Patil Vidyapeeth, 10, 297-299. https://doi.org/10.4103/0975-2870.206576 